\title{
On the fracture toughness of snow
}

\author{
Jürg SCHWEIZER, ${ }^{1}$ Gerard MICHOT, ${ }^{2}$ Helmut O. K. KIRCHNER ${ }^{3}$ \\ ${ }^{1}$ WSL Swiss Federal Institute for Snow and Avalanche Research SLF, Flüelastrasse 11, CH-7260 Davos-Dorf, Switzerland \\ E-mail: schweizer@slf.ch \\ ${ }^{2}$ Laboratoire de Physique des Matériaux, Ecole des Mines, Parc de Saurupt, 54042 Nancy Cedex, France \\ ${ }^{3}$ Institut de Sciences des Matériaux, bâtiment 410, Université Paris-Sud, 91405 Orsay Cedex, France
}

\begin{abstract}
The release of a dry-snow slab avalanche involves brittle fracture. It is therefore essentially a non-linear fracture mechanics problem. Traditional snow-stability evaluation has mainly focused on snow strength measurements. Fracture toughness describes how well a material can withstand failure. The fracture toughness of snow is therefore a key parameter to assess fracture propagation propensity, and hence snow slope stability. Fracture toughness in tension $K_{\text {Ic }}$ and shear $K_{\text {IIc }}$ was determined with notched cantilever-beam experiments in a cold laboratory. Measurements were performed at different temperatures and with different snow types of density $\rho=100-300 \mathrm{~kg} \mathrm{~m}^{-3}$, corresponding to typical dry-snow slab properties. The fracture toughness in tension $K_{\text {Ic }}$ was found to be larger (by about a factor of 1.4 ) than in shear $K_{\text {IIc }}$. Typical values of the fracture toughness were $500-1000 \mathrm{~Pa} \mathrm{~m}^{1 / 2}$ for the snow types tested. This suggests that snow is one of the most brittle materials known to man. A power-law relation of toughness $K_{\text {Ic }}$ on relative density was found with an exponent of about 2 . The fracture toughness in tension $K_{\text {Ic }}$ decreased with increasing temperature following an Arrhenius relation below about $-8^{\circ} \mathrm{C}$ with an apparent activation energy of about $0.16 \mathrm{eV}$. Above $-6^{\circ} \mathrm{C}$ the fracture toughness increased with increasing temperature towards the melting point, i.e. the Arrhenius relation broke down. The key property in dry-snow slab avalanche release, the critical crack size under shear at failure, was estimated to be about $1 \mathrm{~m}$.
\end{abstract}

\section{INTRODUCTION}

Dry-snow slab avalanche release starts with damage accumulation at the interface between a weak snow layer and the overlying slab layer, or alternatively within the (thin) weak layer below the overlying slab (Schweizer and others, 2003). Initial failure formation and consecutive fracture propagation depend on the fracture resistance of the snow layers involved. In linear elastic fracture mechanics (LEFM), the resistance to fracture is generally called fracture toughness; formally it is described by the critical-stress intensity factor $K_{\mathrm{c}}$. The stress intensity factor $K$ defines the crack-tip stress field completely and depends on loading configuration, crack size, crack configuration and component geometry; the critical stress intensity factor $K_{\mathrm{c}}$ is a material parameter and describes a failure criterion (Anderson, 1995). According to the loading configuration, fracture toughness in tension (mode I) $K_{\text {Ic }}$ and in shear (mode II) $K_{\text {IIc }}$ are controlling. In reality, however, fracture in mixed mode dominates in most materials. In avalanche formation, the primary shear fracture is likely determined by $K_{\text {IIc }}$, whereas the secondary fracture of the slab in tension should be determined by $K_{\mathrm{Ic}}$. In the following, the principles of linear fracture mechanics are applied. There are two limitations that must be pointed out when applying LEFM to the dry-snow slab problem. First, in the case of natural release, initial failure formation is not linear elastic, but ductile or viscoelastic. Second, the snowpack is not a homogeneous but a layered material. Therefore, so-called interfacial fracture mechanics developed for laminated materials should rather be applied in the future (Hutchinson and others, 1987).
McClung (1981) was the first to formally introduce the fracture toughness $K_{\text {IIc }}$ in a model of dry-snow slab avalanche release. There were no attempts to measure this important quantity till recently (Kirchner and others, 2000). By performing simple cantilever-beam experiments, Kirchner and others (2000, 2002a, b) successfully made the first measurements of fracture toughness in tension and shear. They concluded that snow would be one of the most brittle materials known to man. Louchet (2001) revisited slab avalanche release, pointed out the importance of fracture toughness, made attempts to measure it and did discrete-element simulations for the experimental set-up (Failletaz and others, 2002). Bazant and others (2003) expanded the model of McClung $(1979,1981)$ and showed that the critical crack length $a_{\mathrm{c}}$, necessary to drive brittle fracturing, should be of the order of the slab thickness $D$. Furthermore, they concluded that the mode II fracture toughness should be proportional to 1.8 power of the slab thickness.

In the present study, we neglect the two above-mentioned limitations and focus on simple cantilever-beam experiments to measure the fracture toughness in tension and shear. The aim is to corroborate and expand the previous findings by Kirchner and others $(2000,2002 a, b)$ and in particular to determine the temperature dependence of the fracture toughness.

\section{METHODS}

Cantilever-beam experiments with snow samples taken from the natural snowpack were performed in the SLF cold laboratory at Weissfluhjoch, Davos, Switzerland. The beams 

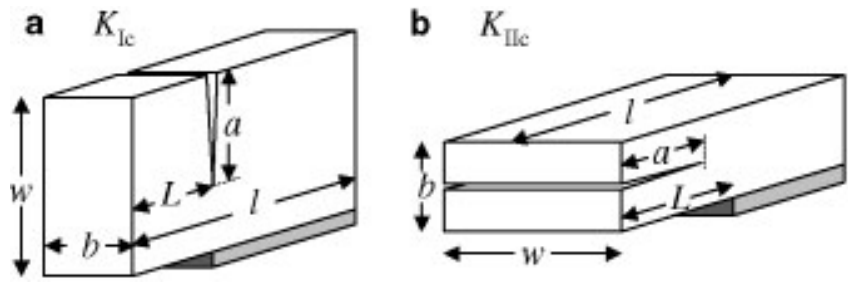

Fig. 1. Geometry of experiments to determine (a) toughness in mode I, $K_{\mathrm{Ic}}$, and (b) toughness in mode II, $K_{\mathrm{IIc}}$. Snow beams were $l=50 \mathrm{~cm}$ long, $w=20 \mathrm{~cm}$ wide and $b=10 \mathrm{~cm}$ thick.

were $l=50 \mathrm{~cm}$ long, with a cross-sectional area of $10 \mathrm{~cm} \times$ $20 \mathrm{~cm}$ (Fig. 1). The samples were taken from the natural snowpack by introducing a mould of the above size with the length $L$ parallel to the layering of the snowpack, i.e. parallel to the snow surface. The aim was to extract samples from a single layer that looked more or less homogeneous. For the experiments, the beams were cantilevered by the length $l$. The beam was then cut at $x=L$ with a fishing line (diameter $<0.1 \mathrm{~mm}$ ). The length of cut when the cantilevered part of the beam broke off, $a_{\mathrm{c}}$, was recorded, as well as the time to break off. The cut was made on average within 2-3 s. At corresponding strain rates, snow is known to be brittle. To determine $K_{\text {Ic }}$ the beams were cantilevered by $L=10-15 \mathrm{~cm}$ and cut perpendicular to the length of the beam (Fig. la). Alternatively, to determine $K_{\text {IIc }}$ the beams were cantilevered by $L=25-30 \mathrm{~cm}$ and cut parallel to the length $l$ of the beam (Fig. 1b).

The critical-stress intensity factors in tension $K_{\text {Ic }}$ and in shear $K_{\text {IIc }}$ were determined as given by Kirchner and others (2002a,b):

$$
K_{\mathrm{Ic}}=\left[F_{\mathrm{l}}\left(\frac{P+G}{w b}\right)+F\left(\frac{6 M}{w^{2}}\right)\right] \sqrt{\pi a_{\mathrm{c}}}
$$

and

$$
K_{\mathrm{IIc}}=\frac{3}{4}(\rho g b+p) a_{\mathrm{c}}^{2}\left(\frac{b}{2}\right)^{-\frac{3}{2}},
$$

where $F_{\mathrm{I}}$ and $F$ are geometrical factors depending on $a_{\mathrm{c}} / w$ (Kirchner and others, 2002a, fig. 5), and $M$ is the moment created by the weight $G$ of the cantilever. All experiments in the present study were performed without additional external loading $(P=p=0)$, but subjected to body forces only. No mixed mode is considered in these tests.

Equation (1) is for the vertical, as in Figure la, and Equation (2) for the horizontal cut, as in Figure 1b. Both equations are derived on the level of beam theory, i.e. on the level of an overall equilibrium of forces and moments. So far, no finite-element calculations, which would be on the level of local force equilibrium, have been published. Such calculations, for finite beam size and body loading, would presumably show that some combination of fracture modes is present. In the geometry of Figure la, some vertical shear must in principle be present, because the beam is not infinitely long and the crack plane is not a symmetry plane. The weight of the snow close to the crack produces shear, and the snow far away from the crack produces the moment and tension; the former is neglected in Equation (1). For the geometry of Figure 1b, Equation (2) merely compares the elastic energy of two half-beams with the energy of a full beam. The actual stress distribution around the crack is not being considered in detail. Nevertheless, since beam theory,
Table 1. Summary of number and type of experiments performed of a certain snow type, density range (interquartile

\begin{tabular}{|c|c|c|c|c|c|}
\hline Series & $\begin{array}{l}\text { Number of } \\
\text { experiments } \\
N\end{array}$ & $\begin{array}{l}\text { Type of ex- } \\
\text { periment }\end{array}$ & Snow type & $\begin{array}{l}\text { Density } \\
\text { range } \\
\mathrm{kg} \mathrm{m}^{-3}\end{array}$ & $\begin{array}{c}\text { Snow tem- } \\
\text { perature } \\
{ }^{\circ} \mathrm{C}\end{array}$ \\
\hline A & 26 & $K_{\text {Ic }}, K_{\text {IIc }}$ & $\begin{array}{l}\text { Small rounded, partly } \\
\text { decomposed and frag- } \\
\text { mented, } 0.25-0.75 \mathrm{~mm} \text {, } \\
\mathrm{F}-4 \mathrm{~F}\end{array}$ & $200-215$ & -9.4 \\
\hline B & 10 & $K_{\mathrm{Ic}}, K_{\mathrm{IIc}}$ & $\begin{array}{l}\text { Small rounded, partly } \\
\text { decomposed and frag- } \\
\text { mented, } 0.25-0.75 \mathrm{~mm} \text {, } \\
4 \mathrm{~F}\end{array}$ & $250-260$ & -10.0 \\
\hline C & 18 & $K_{\text {Ic }}$ & $\begin{array}{l}\text { Decomposed and frag- } \\
\text { mented, partly new } \\
\text { snow, } 0.5-0.8 \mathrm{~mm}, \mathrm{~F}\end{array}$ & $70-90$ & -9.0 \\
\hline $\mathrm{D}$ & 12 & $K_{\text {Ic }}, K_{\text {IIc }}$ & $\begin{array}{l}\text { Small rounded, partly } \\
\text { decomposed and frag- } \\
\text { mented, } 0.4-0.7 \mathrm{~mm} \text {, } \\
4 \mathrm{~F}-1 \mathrm{~F}\end{array}$ & $170-200$ & -9.2 \\
\hline $\mathrm{E}$ & 12 & $K_{\text {Ic }}, K_{\text {IIc }}$ & $\begin{array}{l}\text { Small rounded, } \\
0.25-0.5 \mathrm{~mm}, 1 \mathrm{~F}-\end{array}$ & $200-220$ & -9.3 \\
\hline $\mathrm{F}$ & 6 & $K_{\text {Ic }}, K_{\text {IIc }}$ & $\begin{array}{l}\text { Small rounded, } \\
0.25-0.4 \mathrm{~mm}, 1 \mathrm{~F}\end{array}$ & $250-260$ & -9.5 \\
\hline G & 66 & $K_{\text {Ic }}$ & $\begin{array}{l}\text { Small rounded, } \\
0.25-0.4 \mathrm{~mm}, 1 \mathrm{~F}+\end{array}$ & 270-280 & $\begin{array}{c}-18.5 \text { to } \\
-2.2\end{array}$ \\
\hline
\end{tabular}
range is given) and snow temperature

Note: Snow type is given as grain shape, grain-size and hardness (hand test) according to ICSSG (Colbeck and others, 1990).

although usually difficult to justify, usually works in structural mechanics, we proceed on this level. In addition, the configuration we use for the $K_{\text {IIc }}$ measurements corresponds to the double cantilever-beam specimen which is currently the common type of test for interlaminar mode II fracture toughness measurements (Anderson, 1995, p. 447449).

The standard size requirements for a valid $K_{\text {Ic }}$ are as follows (Anderson, 1995, p. 376):

$$
b, a \geq 2.5\left(\frac{K_{\mathrm{Ic}}}{\sigma_{\mathrm{s}}}\right)^{2} \quad 0.45 \leq a / w \leq 0.55,
$$

where $\sigma_{\mathrm{s}}$ is the tensile strength. For a snow density of $200 \mathrm{~kg} \mathrm{~m}^{-3}$, the ratio of toughness to strength in Equation (3) is about $0.44\left(\sigma_{\mathrm{s}} \approx 2 \mathrm{kPa}\right)$ (Jamieson and Johnston, 1990). Accordingly, the snow beams we used were too small to fulfil the size requirements. However, the snow beams to be used according to the standard size requirements would be too large for feasible experiments, in particular with specimens from the natural snow cover.

\section{MEASUREMENTS}

Seven series $(\mathrm{A}-\mathrm{G})$ of experiments were performed between January 2002 and February 2003 (Table 1). Snow type was classified according to the International Classification for Seasonal Snow on the Ground (ICSSG; Colbeck and others, 1990). Density was determined by weighing the part of the beam that broke off. For each series of experiments, the interquartile range of density is given in Table 1. Occasionally (consistently for series A and B), hardness as resistance to penetration was determined using a hand-held force gauge with a disc-shaped penetrometer $\left(1.17 \mathrm{~cm}^{2}\right.$ cross- 

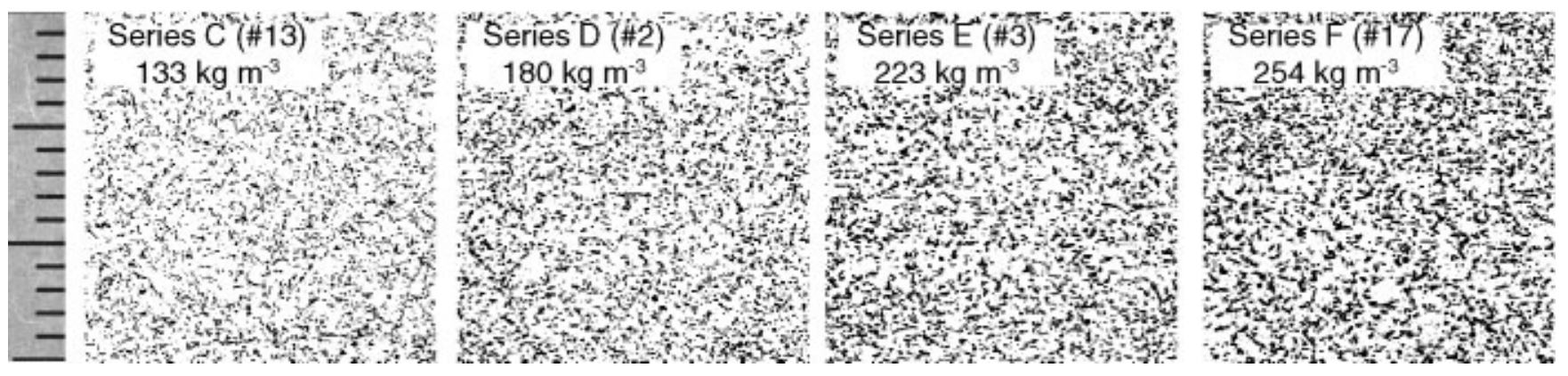

Fig. 2. Microstructure of snow types tested: series $C, D, E$ and $F$ (left to right). Binarized pictures of surface sections. Black denotes ice; white is pore space. Scale given is $15 \mathrm{~mm}$. Density given was determined with image-analysis procedures.

sectional area). Hardness values ranged from 1.1 to $57 \mathrm{kPa}$. As samples were taken from the natural snow cover, they were not homogeneous, but typically included some layering. Whereas this layering is preferable for mode II experiments where the cut is parallel to the layering, it is a substantial source of undesirable variation in mode I experiments. The effect of layering was checked in the experiments of series A (see below). After this initial series of experiments, in all the following experiments the layering was parallel to the width $w=20 \mathrm{~cm}$ of the beams. Accordingly, in the mode I experiments the snow layering did not substantially affect the results. Snow temperatures at the time of harvesting were between -9 and $-13^{\circ} \mathrm{C}$. After sampling, the beams were either tested the same day or stored for up to 3 days at $-20^{\circ} \mathrm{C}$ in the cold laboratory to avoid further metamorphism. Snow temperature at the time of testing was about -9 to $-10^{\circ} \mathrm{C}$, or varied (series $\mathrm{G}$, Table 1). In order to further characterize the snow texture, samples from some beams were preserved in diethyl phthalate and analyzed with the surface section technique (Good, 1987). Density was determined with image-analysis procedures.

\section{RESULTS}

\section{Snow characterization}

Sample characterization in the cold laboratory by surface section analysis supported the traditional classification according to the ICSSG (Colbeck and others, 1990). Exemplary surface sections from samples of series $\mathrm{C}-\mathrm{F}$ are shown in Figure 2. Densities of these samples, determined with image analysis, were: for series $\mathrm{C} 133 \mathrm{~kg} \mathrm{~m}^{-3}$; for series D $180 \mathrm{~kg} \mathrm{~m}^{-3}$; for series $\mathrm{E} 221 \mathrm{~kg} \mathrm{~m}^{-3}$, and for series $\mathrm{F}$ $254 \mathrm{~kg} \mathrm{~m}^{-3}$. These values agree well with the densities measured in the cold laboratory, except for series $\mathrm{C}$ (Table 1). Series $\mathrm{C}$ consisted of decomposed, fragmented particles of recently deposited, low-density snow for which the density is more difficult to determine with image-analysis methods than for well-consolidated snow.

\section{Effect of stratigraphy and geometry}

The tests with the beams of series A showed substantial dependence on the orientation of the layering and the test geometry (Fig. 3). In the case when the layering was parallel to $b$, the fracture toughness in tension $K_{\text {Ic }}$ was much smaller when the beams were tested upside down (rotated by $180^{\circ}$ ), regardless of whether the beams were cantilevered by $L=$ $10 \mathrm{~cm}$ or $L=15 \mathrm{~cm}$. This was due to the distinct layering since it was impossible to have a homogeneous layer of $20 \mathrm{~cm}$ thickness within the snowpack. Since the density increased with increasing depth, the orientation of the beams affected the results. This also explains the different results due to the orientation of the layering. When the layering was parallel to $w$, the toughness $K_{\text {Ic }}$ values were lower, since they represent an average value, than when the layering was parallel to $b$. In the latter case, the harder, denser snow towards the bottom of the beam determined the toughness, since the crack tip was within these layers, when the beam failed.

Not only the layering but also the geometry, i.e. the amount of cantilevering, affected the results. Toughness values for $L=15 \mathrm{~cm}$ were substantially larger than for $L=10 \mathrm{~cm}$. This shows that Equation (1) with the accompanying geometrical factors $F$ and $F_{\mathrm{I}}$ is only an approximate solution for the geometry used in our experiments. This finding is in accordance with preliminary results by Failletaz and others (2002). Further analysis showed that the difference was systematic and can be corrected. Values obtained with $L=15 \mathrm{~cm}$ were multiplied by a factor 0.6 , so that they can be compared to values obtained with $L=$ $10 \mathrm{~cm}$. In the following, all values given for $K_{\text {Ic }}$ were obtained with $L=10 \mathrm{~cm}$ or accordingly adjusted. However, this also means that our $K_{\text {Ic }}$ values represent order-of-magnitude values, and should be used with caution.

Also given in Figure 3 are a few values for the fracture

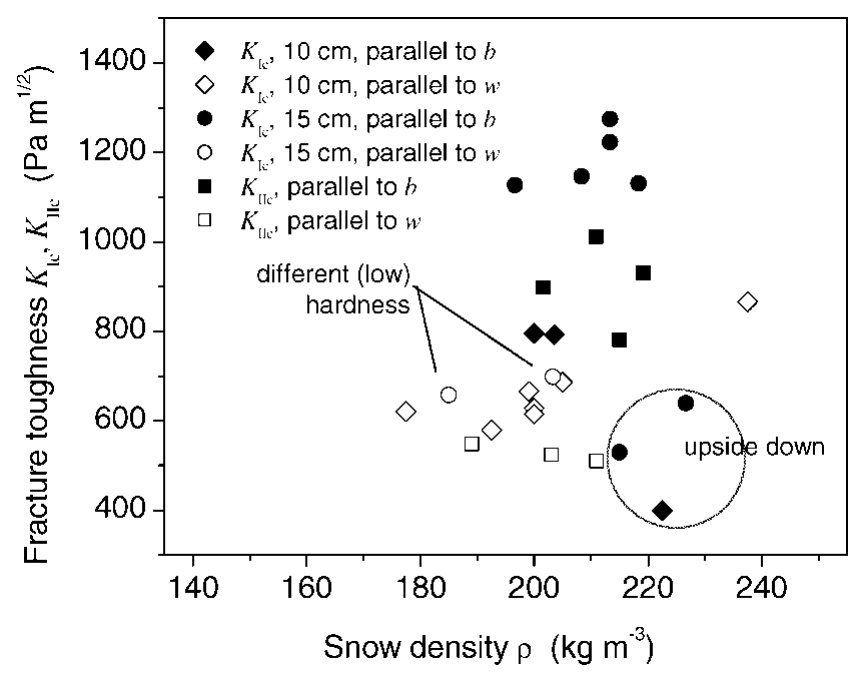

Fig. 3. Fracture toughness in tension $K_{\text {Ic }}$ and in shear $K_{\text {IIc }}$ for different orientation of layering (parallel to $b$ or $w$; see Fig. 1) and for two cantilever lengths $L=10 \mathrm{~cm}$ and $L=15 \mathrm{~cm}\left(K_{\mathrm{Ic}}\right.$ only). Data from series $A$ and $B$. 


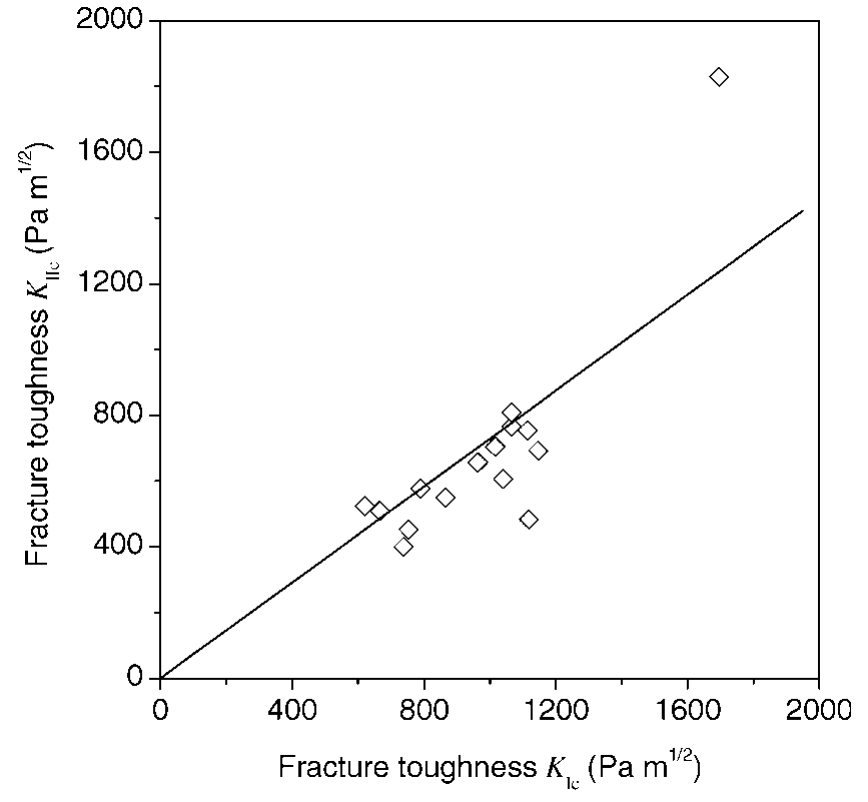

Fig. 4. Comparison of fracture toughness in tension $K_{\mathrm{Ic}}$ to fracture toughness in shear $K_{\mathrm{IIc}}$ determined in pairs from the same beams. The line indicates the linear regression with a slope of 0.73. Data from series $A$ and $B$.

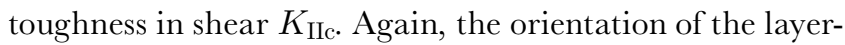
ing affected the results. When the layering was parallel to $w$, the orientation that is most realistic for our problem, parallel to the crack plane, the values of the fracture toughness were smaller than when the layering was perpendicular to the crack plane. This result is reasonable and reflects the fact that snow is a layered material which is most susceptible to failure parallel to the layering.

\section{Fracture toughness in tension and shear}

A limited number of beams $(N=15)$ of series $\mathrm{A}$ and $\mathrm{B}$ (Table 1) were tested first under shear, and after the shear fracture had occurred the remainder of the beam was tested under tension. For all beams the layering was parallel to $w$, i.e. the cut was made parallel to the layering to determine $K_{\text {IIc. }}$ This series of experiments allows a direct comparison between the fracture toughness in tension and the fracture toughness in shear (Fig. 4), both being measured on the same specimen and thus hardly influenced by snow type. According to the linear regression shown in Figure 4, the ratio of $K_{\text {IIc }}$ to $K_{\text {Ic }}$ is $0.73 \pm 0.05$ (coefficient of correlation: $r=0.86$; level of significance: $p<0.001$ ). The fracture toughness in tension is about 1.4 times larger than the fracture toughness in shear. Density varied between 165 and $265 \mathrm{~kg} \mathrm{~m}^{-3}$, with an average density of $220 \mathrm{~kg} \mathrm{~m}^{-3}$. The ratio of $K_{\text {Ic }}$ to $K_{\text {IIc }}$ was independent of density (level of significance: $p=0.78$ ).

\section{Fracture toughness in tension related to density}

Experiments of series $\mathrm{A}-\mathrm{F}$ were used to determine the relation of the fracture toughness in tension $K_{\text {Ic }}$ to snow density. Series $\mathrm{C}-\mathrm{F}$ were specifically chosen to determine the density dependence. They cover a wide range of snow density: $80-250 \mathrm{~kg} \mathrm{~m}^{-3}$, relevant for the snow slab release problem. All tests were performed at about -9 to $-10^{\circ} \mathrm{C}$, with the layering parallel to $w$. All beams were cantilevered by $L=10 \mathrm{~cm}$. Series A and B were performed with low-

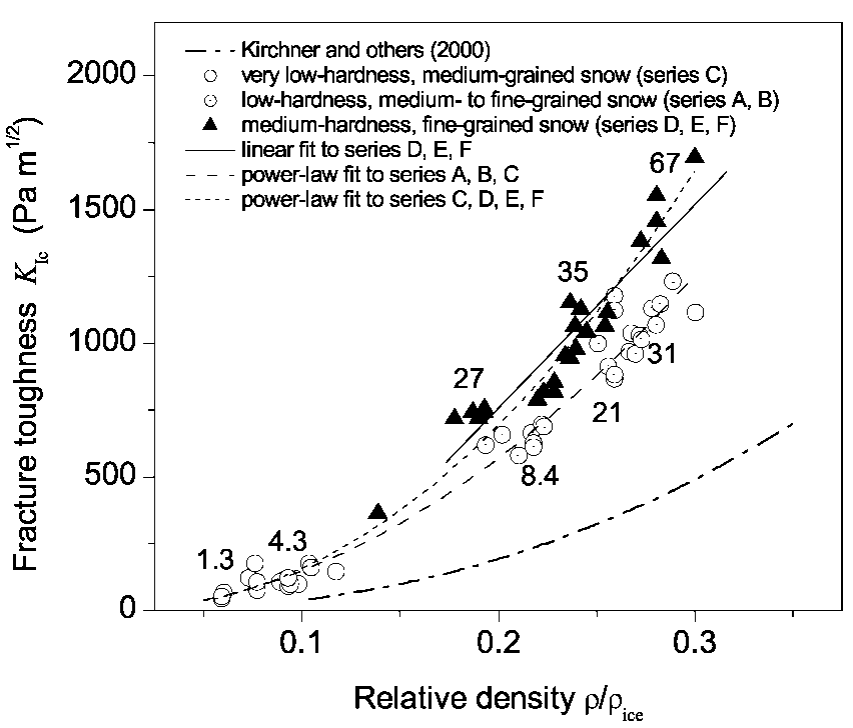

Fig. 5. Fracture toughness $K_{\mathrm{Ic}}$ in relation to relative snow density $\rho / \rho_{\text {ice }}$ for different snow types. Data from series $A-F$. For comparison the relationship found by Kirchner and others (2000) is given (obtained with different snow types at different temperature). Two power-law relations are fitted to the data. The bold straight line is a linear fit to series $D-F$ and subsequently used to normalize values of series $G$. Numbers indicate snow hardness in $k P a$ determined with a force gauge.

hardness, medium- to fine-grained snow. The beams of series C consisted of low-density, low-hardness mediumgrained snow. The snow in series D-Fexperiments was from well-consolidated, relatively dense and hard layers of finegrained snow. It was expected that the dependence on density would be affected by the different snow types. The data are compiled in Figure 5, taking into account the snow type. Mean hardness values, determined with the force gauge, are also given, showing the increase of hardness with increasing density independent of snow type. The dependence of fracture toughness on density is non-linear. Although density alone is not an ideal predictor for any mechanical property of snow (Shapiro and others, 1997), a good fit of mechanical properties with density has traditionally been obtained with a power-law relation (Perla and others, 1982; Jamieson and Johnston, 2001):

$$
K_{\text {Ic }}=A\left(\frac{\rho}{\rho_{\text {ice }}}\right)^{B},
$$

where $\rho_{\text {ice }}$ is the density of ice $\left(917 \mathrm{~kg} \mathrm{~m}^{-3}\right)$ and $A$ and $B$ are empirical constants that depend on snow type. Kirchner and others (2000) also used a power-law relation and found for their data: $A=7.84 \mathrm{kPa} \mathrm{m}^{1 / 2}$ and $B=2.3$. Their results were obtained with field tests at temperatures near the melting point, and with snow types that are not known in detail but were substantially different from ours.

A power-law fit to series $\mathrm{A}-\mathrm{C}$, i.e. to the $K_{\text {Ic }}$ values obtained from experiments with rather soft and mediumto fine-grained snow, revealed (dashed line in Fig. 5):

$$
K_{\text {Ic }}=A_{1}\left(\frac{\rho}{\rho_{\text {ice }}}\right)^{1.9} \text {. }
$$

with $A_{1}=13.0 \mathrm{kPa} \mathrm{m}^{1 / 2}$. Alternatively, combining series $\mathrm{C}_{-}$ Fresulted in the following density relation representative for 
medium hard and fine-grained snow (short-dashed line in Fig. 5):

$$
K_{\text {Ic }}=A_{2}\left(\frac{\rho}{\rho_{\text {ice }}}\right)^{2.1} .
$$

with $A_{2}=21.6 \mathrm{kPa} \mathrm{m}^{1 / 2}$. The goodness of fit for both relations is high (coefficient of correlation: $r=0.98$ ). Whereas the power-law fit is ideal if a wide range of density needs to be covered, a linear fit for a limited range of density (e.g. $\left.200-300 \mathrm{~kg} \mathrm{~m}^{-3}\right)$ is sufficient and nearly as good $(r=0.94)$. Accordingly, in the following, when analyzing the temperature effect, a linear relation will be used (bold line in Fig. 5) to take into account the density dependence:

$$
K_{\text {Ic }}=A_{3}\left(\frac{\rho}{\rho_{\text {ice }}}\right)+C^{\prime} .
$$

with $A_{3}=7.63 \mathrm{kPam}^{1 / 2}$ and $C^{\prime}=-0.769 \mathrm{kPa} \mathrm{m}^{1 / 2}$.

The results in Figure 5 suggest a strong dependence on snow type. In fact, toughness decreases with increasing grain-size, as about $d_{\max }^{-1 / 2}$, with $d_{\max }$ being the upper range value of grain-size given in Table 1 . Accordingly, the density dependence of our data on fracture toughness $K_{\text {Ic }}$ can be described as $(r=0.98)$ :

$$
K_{\text {Ic }}=\frac{A_{4}}{\sqrt{d_{\max }}}\left(\frac{\rho}{\rho_{\text {ice }}}\right)^{1.9} .
$$

with $A_{4}=0.35 \mathrm{kPam}$.

To check whether snow hardness, or hardness and density combined, was a better predictor than density alone, hardness was measured systematically for series $\mathrm{A}$ and $\mathrm{B}$ $(N=24)$. A multiple linear regression for $K_{\text {Ic }}$ with density and hardness as independent variables showed that hardness was of minor importance compared to density (correlation not significant), and accordingly did not improve the correlation. This is due to the high correlation of density with hardness. Also, a regression of hardness alone as independent variable with toughness revealed a lower coefficient of correlation than with density alone.

\section{Fracture toughness in tension related to snow tem- perature}

The temperature effect on the fracture toughness is of primary importance to the avalanche release problem. No attempts have previously been made to experimentally determine the relation of fracture toughness to snow temperature. At nine temperatures between $-18^{\circ}$ and $-2^{\circ} \mathrm{C}$ a total of 66 measurements of the fracture toughness in tension $K_{\text {Ic }}$ were made (series $\mathrm{G}$ ). Between 3 and 11 measurements were made at a given snow temperature. Beams were cantilevered by $L=10$ or $15 \mathrm{~cm}$; values obtained with $L=15 \mathrm{~cm}$ were adjusted based on the systematic difference to values with $L=10 \mathrm{~cm}$ (see above). The beams were cut out of a relatively dense, well-consolidated layer of small rounded grains with an average density of $277 \pm 19 \mathrm{~kg} \mathrm{~m}^{-3}$. This density variation influenced the temperature effect. Assuming that the density and temperature effects were independent, the fracture toughness can be given as:

$$
K_{\mathrm{Ic}}(\theta, \rho)=f(\theta)+g(\rho) \text {. }
$$

Using Equation (6) for the density dependence, all fracture toughness values were normalized to a density of $\rho_{0}=$ $275 \mathrm{~kg} \mathrm{~m}^{-3}$. So, values of the fracture toughness in tension given below were adjusted to $L=10 \mathrm{~cm}$ and normalized to $\rho_{0}=275 \mathrm{~kg} \mathrm{~m}^{-3}$, and denoted as $K_{\mathrm{Ic}}^{*}$.

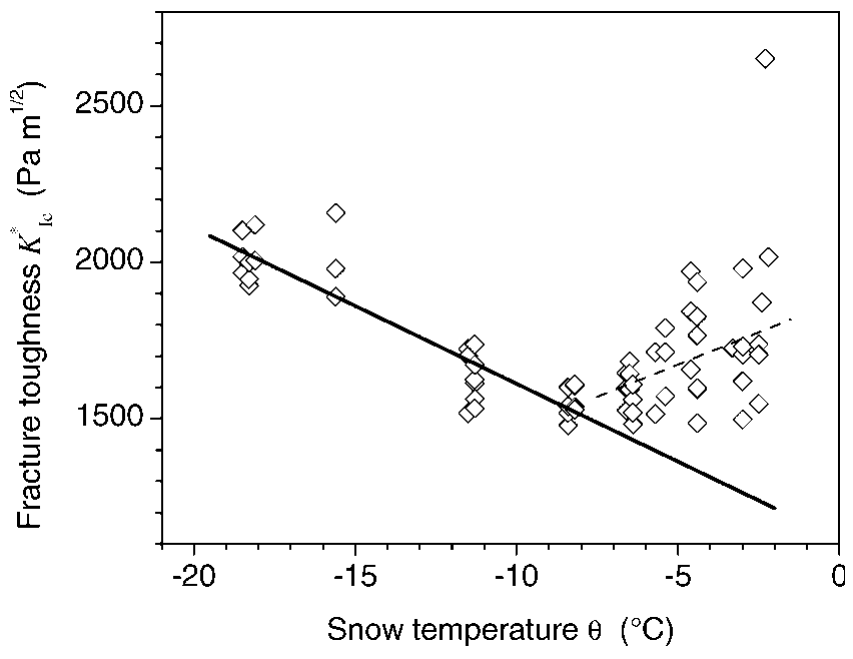

Fig. 6. Temperature dependence of the fracture toughness $K_{\mathrm{Ic}}^{*}$ normalized to $\rho_{0}=275 \mathrm{~kg} \mathrm{~m}^{-3}$ and adjusted for cantilever length $L=10 \mathrm{~cm}$. Bold solid line is a linear fit to data below $-8^{\circ} \mathrm{C}$. Dashed line indicates linear fit to data above $-6^{\circ} \mathrm{C}$. Data of series $G$.

At a given temperature there was an average variation between the different measurements of about 7\% (coefficient of variation). The coefficients of variation were relatively low compared with other snow mechanical measurements (e.g. of the shear strength (coefficient of variation typically 15-20\%)) (Jamieson and Johnston, 2001). The variation increased with increasing temperature. It was typically $4-5 \%$ at the lower temperatures and increased to about $10 \%$ at the temperatures near the melting point.

Figure 6 shows that the fracture toughness $K_{\text {Ic }}^{*}$ clearly decreased with increasing temperature up to about $-8^{\circ} \mathrm{C}$. For temperatures higher than about $-6^{\circ} \mathrm{C}$, i.e. towards the melting point, the fracture toughness $K_{\mathrm{Ic}}^{*}$ increased. For the temperature range -18 to $-8^{\circ} \mathrm{C}$ the linear decreasing trend was highly significant $(\mathrm{p}<0.0001)$. The coefficients of the linear relation $K_{\mathrm{Ic}}^{*}=a \theta+d$ were $a=-49.7 \mathrm{kPa} \mathrm{m}^{1 / 2}{ }^{\circ} \mathrm{C}^{-1}$ and $d=1115 \mathrm{kPa} \mathrm{m}^{1 / 2}$. This means that the fracture toughness decreased by about $25 \%$ when the temperature increased by about $10^{\circ} \mathrm{C}$. Above $-6^{\circ} \mathrm{C}$, there was a trend to increasing toughness with increasing temperature that was, despite large scatter, statistically significant $(N=37$, $r=0.436, p=0.007$ ). It could not be shown that the fracture toughness eventually decreases again towards the melting point.

Alternatively, based on the temperature dependence of the creep of ice, the temperature dependence can be described with an Arrhenius relation (Hooke and others, 1980):

$$
K_{\text {Ic }}=C \exp \left(\frac{Q}{R T}\right),
$$

where $Q$ is the activation energy for creep and $R$ is the gas constant. This relation is physically reasonable, but is known to break down at temperatures above -8 to $-6^{\circ} \mathrm{C}$. Accordingly, Figure 7 shows the fracture toughness $K_{\text {Ic }}^{*}$ on a logarithmic scale vs the inverse of the absolute temperature $T$. If a linear relationship is found, the fracture toughness follows the Arrhenius relation, i.e. the slope corresponds to $Q / R$. In fact, the data followed Equation (10) up to about $-8^{\circ} \mathrm{C}$ with a slope of $1880 \pm 160 \mathrm{~K}^{-1}(N=$ 28, $r=0.91, p<0.0001)$. This corresponds to an apparent 


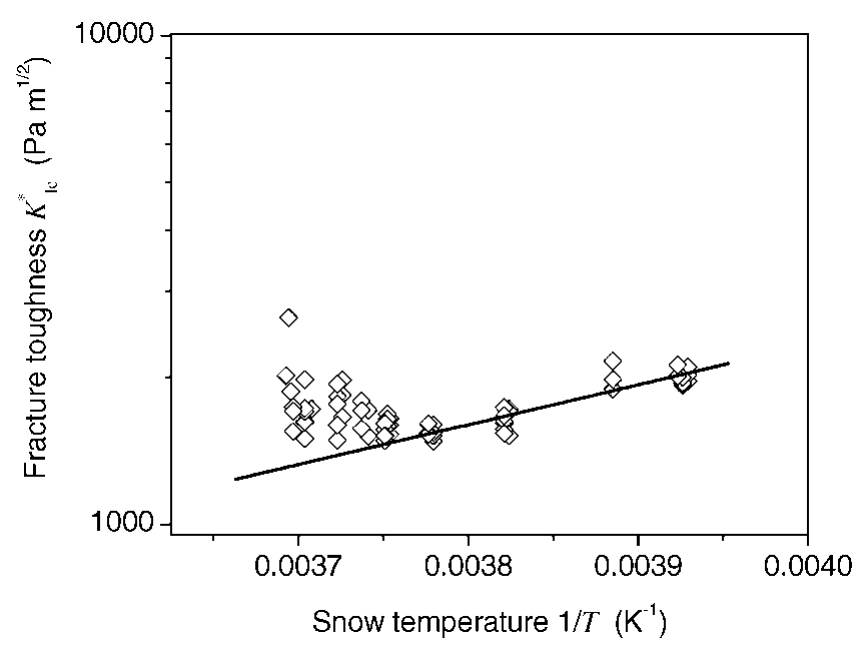

Fig. 7. Fracture toughness $K_{\mathrm{Ic}}^{*}$ on a semi-logarithmic scale vs the inverse of the absolute temperature T (so-called Arrhenius plot). Apparent linear fit for data below $-8^{\circ} \mathrm{C}$ indicates that the data follow an Arrhenius relation with an apparent activation energy of $Q=0.16 \mathrm{eV}$. Data of series $G$, as in Figure 6 .

activation energy $Q$ of about $0.16 \mathrm{eV}$ (activation energy for self-diffusion of ice: about $0.6 \mathrm{eV}$ ). Above $-8^{\circ} \mathrm{C}$ the fracture toughness increased, i.e. the Arrhenius relation breaks down.

\section{DISGUSSION AND CONCLUSIONS}

The measurements of fracture toughness in tension and shear under controlled conditions in a cold laboratory with cantilevered snow beams from a natural snowpack showed that this type of measurement is suited to determine this highly relevant parameter for the snow slab release problem. However, despite the experimental simplicity and good reproducibility of the experiments, some doubts remain on the absolute values based on the analysis presented above, due to the dependence on the cantilever length, the possible presence of mixed mode fracture and the unfulfilled size requirements. In the absence of finite-element simulations of the stress distribution in the experimental set-up, these doubts have to be accepted, and the toughness values given above must be considered order-of-magnitude values rather than absolute values.

One of the main problems is that a combination of fracture modes is present. The vertical cut to determine $K_{\text {Ic }}$ (Fig. la) does not produce tension only, so that Equation (1) is incomplete in principle. Correspondingly, the same is true for the horizontal cut (Fig. lb). Once the critical length $a_{\mathrm{c}}$ has been cut, the cantilever breaks off almost vertically in the geometry of Figure la. If the loading were entirely in mode I, the fracture surface should be perfectly vertical, but it is not, indicating some minor presence of mode II. In the case of the test configuration of Figure $1 b$ to determine $K_{\text {IIc }}$, once the critical crack length $a_{\mathrm{c}}$ has been cut, the crack should continue horizontally, as it should if mode II were perfect, before becoming unstable so that here also the beam breaks off vertically. This instability is due to breaking of the shear antisymmetry, suggesting that some parasitic mode I contributes.

Nevertheless, we are confident that our results on the ratio of tension to shear toughness, the relation to density and to temperature reflect the true physical behaviour. The following discussion aims to confirm this.

The ratio of tension to shear toughness, about 1.4, is well in agreement with the ratio of tensile to shear strength. Tensile strength is about $50-100 \%$ larger than shear strength for a given density range (Jamieson and Johnston, 1990, 2001). This is somewhat different from other materials where the toughness in tension is usually lower than the toughness in shear. The high degree of layering in natural snow cover may be responsible for the relatively low strength and toughness under shear. This therefore may reflect to a certain degree a geometrical effect rather than a material property.

The exponents in the power-law relations of toughness vs relative density $\rho / \rho_{\text {ice, }}$ about 2.0 , were similar to those found for other snow mechanical properties, such as the shear strength (Jamieson and Johnston, 2001). They reported exponents of 1.7 and 2.1 depending on snow type. Considering snow as a foam (Kirchner and others, 2001), it can be postulated, based on the fundamental work of Gibson and Ashby (1997) for brittle polymeric foams, that

$$
\frac{K_{\text {Ic }}}{K_{\text {Icice }}} \propto\left(\frac{\rho}{\rho_{\text {ice }}}\right)^{1 / 2}\left(\frac{E}{E_{\text {ice }}}\right)^{1 / 2}=\left(\frac{\rho}{\rho_{\text {ice }}}\right)^{3 / 2},
$$

thereby assuming that the ratio of the elastic modulus of snow to the modulus of ice $E / E_{\text {ice }}$ should be proportional to $\left(\rho / \rho_{\text {ice }}\right)^{2}$. Similarly, again for an ideal open-cell foam, the strength of snow should show the same behaviour as the fracture toughness, i.e. be proportional to $\left(\rho / \rho_{\text {ice }}\right)^{3 / 2}$. There is, however, experimental evidence that for Young's modulus of snow the exponent is larger than 2, that is about 4 (Kojima, 1954; Camponovo and Schweizer, 2001). Accordingly, in Equation (11), the exponent should be about 2.5 rather than 1.5. Our values of the exponent for the fracture toughness, as well as those by Jamieson and Johnston (2001) for the shear strength, were well within this theoretical range. Also, assuming an exponent of 2.5 means that the fracture toughness of snow should be about two orders of magnitude lower than the fracture toughness of ice. Nixon and Schulson (1987) tested notched specimens at high strain rates and found that for ice at $-10^{\circ} \mathrm{C} K_{\mathrm{I}_{\mathrm{ice}}} \approx 0.08 \mathrm{MPa} \mathrm{m}^{1 / 2}$. Accordingly, our values were well within the range expected from their results.

The fracture toughness $K_{\text {Ic }}$ was proportional to maximal grain-size $d_{\max }^{1 / 2}$. By including this simple measure of snow microstructure, a single relation (Equation (8)) could be found to describe the density dependence and therefore replaces Equations (5) and (6). The dependence on $d_{\max }^{1 / 2}$ is in agreement with results on ice (Petrenko and Whitworth, 1999).

The fracture toughness in tension $K_{\text {Ic }}$ decreased with increasing temperature following an Arrhenius relation below about $-8^{\circ} \mathrm{C}$ with an apparent activation energy of about $0.16 \mathrm{eV}$. This behaviour was expected based on the temperature dependence of the elastic modulus (Schweizer, 1998; Schweizer and Camponovo, 2002) and the fact that the fracture toughness is closely related to the modulus (Anderson, 1995):

$$
G=\frac{K_{\mathrm{Ic}}^{2}}{E}
$$

where $G$ is the energy release rate. Accordingly, the fracture toughness is proportional to the square root of the modulus. Consequently, McClung and Schweizer (1999) proposed 
that the fracture toughness should decrease with increasing temperature, based on the fact that the modulus is strongly decreasing with increasing temperature. This has in fact now been observed. However, above about $-6^{\circ} \mathrm{C}$ up to the melting point the modulus strongly decreased with increasing temperature, whereas the fracture toughness no longer decreased, but increased. This different behaviour might well have the same roots. In the case of the modulus, the increased deformation towards the melting point is usually associated with the presence of water in ice, and it may be related to pre-melting phenomena at the grain boundaries. In general, however, the interpretation of the deformation processes acting as the melting point is approached is not yet well developed (Petrenko and Whitworth, 1999). These processes increasing the ease of deformation will likely increase the fracture resistance. Also, plastic effects at the crack tip may start to play a more important role. The above finding is in agreement with observations on snow slab release. There is clear experimental evidence that the artificial triggering of snow slab avalanches by explosives becomes much more inefficient with increasing snow temperature (Gubler, 1977).

The modulus has been found to be the most temperaturedependent mechanical property in the avalanche release problem (Schweizer, 1998). A decrease of the snow temperature by $10^{\circ} \mathrm{C}$ increased the modulus by about $100 \%$. Accordingly, the fracture toughness, being proportional to the square root of the modulus, should increase by about $40 \%$. In fact, our analysis showed that the fracture toughness increased by about $33 \%$, which is in fair agreement.

One of the key questions in slab avalanche release is that on the critical crack size at failure. This is particularly relevant to assess the effect of snowpack variability on avalanche formation (Kronholm and Schweizer, 2003). Recently, Bazant and others (2003) have postulated that the critical crack size $a_{\mathrm{c}}$ should be at least as large as the slab thickness $D$, but that the ratio $a_{\mathrm{c}} / D$ should not be much larger than 1 . They also provided an expression for the nominal shear stress $\tau$ at failure that takes into account the size effect, and accordingly the critical crack size $a_{\mathrm{c}}$ can be derived:

$$
a_{\mathrm{c}}=\frac{K_{\mathrm{IIc}} \sqrt{2} D}{\tau}
$$

For typical values slab density $\rho=170 \mathrm{~kg} \mathrm{~m}^{-3}$, slab thickness $D=0.5 \mathrm{~m}$ and slope angle $\psi=38^{\circ}$, the shear stress becomes about $0.5 \mathrm{kPa}$ so that Equation (13) provides a critical crack size of about $1 \mathrm{~m}$, assuming a fracture toughness in shear of $0.5 \mathrm{kPa} \mathrm{m}^{1 / 2}$. This value is slightly larger than what has been previously proposed (Kirchner and others, 2002a), but well within the range that has been previously postulated (McClung and Schweizer, 1999; Schweizer, 1999; Schweizer and Camponovo, 2001). It is also in agreement with the above finding on the ratio $a_{\mathrm{c}} / D$ by Bazant and others (2003). Equation (13) suggests that for a larger slab thickness than considered above, and a given fracture toughness, the critical crack length decreases. However, Bazant and others (2003) concluded that $K_{\text {IIc }}$ should be proportional to $D^{1.8}$ based on Perla's (1977) field measurements, since an increase in thickness should go along with a stronger, denser slab. The above-derived critical crack length should be considered an estimate at best. It is expected that the shear toughness for critical weaknesses in the snowpack should be lower and that absolute actual values of the shear toughness might be higher than those determined from a small specimen.

Summing up, we have for the first time determined the temperature dependence of the fracture toughness $K_{\text {Ic }}$ for snow. The dependence of toughness on density was found to follow a power-law relation. By including a simple measure of snow microstructure, the maximal grain-size $d_{\max }$, a single relation (Equation (8)) described the density dependence for all the various snow types tested. Finally, the toughness in shear was found to be smaller than the toughness in tension. Relating our measurements to the critical crack length at failure, one of the most debated questions in avalanche formation, reveals that our estimate $\left(a_{\mathrm{c}} \approx 1 \mathrm{~m}\right)$ is well in agreement with independent estimates of the critical crack length. For the future, more sophisticated experiments will be needed, together with finite-element calculations to corroborate these results. A possible size effect, as known from concrete, should be addressed, and consequences for avalanche release should be studied, in particular by applying interfacial fracture mechanics. Eventually, fracture toughness needs to be incorporated into snow-slab stability evaluation procedures.

\section{ACKNOWLEDGEMENTS}

G. Krüsi prepared and M. Schneebeli analyzed the surface sections. A. Heilig, E. Hegglin and C. Sigrist helped with the experiments. Their contributions are gratefully acknowledged. We thank R. L. Brown and E. E. Adams for helpful suggestions.

\section{REFERENGES}

Anderson, T. L. 1995. Fracture mechanics: fundamentals and applications. Second edition. Boca Raton, FL, CRC Press.

Bazant, Z. P., G. Zi and D. M. McClung. 2003. Size effect law and fracture mechanics of the triggering of dry slab snow avalanches. 7. Geophys. Res., 108 (B2), 2119-2229. (10.1029/2002]B001884.)

Camponovo, C. and J. Schweizer. 2001. Rheological measurements of the viscoelastic properties of snow. Ann. Glaciol., 32, 44-50.

Colbeck, S. C. and 7 others. 1990. The international classification for seasonal snow on the ground. Wallingford, Oxfordshire, International Association of Scientific Hydrology. International Commission on Snow and Ice.

Faillettaz, J., D. Daudon, D. Bonjean and F. Louchet. 2002. Snow toughness measurements and possible applications to avalanche triggering. In Stevens, J. R., ed. International Snow Science Workshop 2002, 29 September-4 October 2002, Penticton, British Columbia. Proceedings. Victoria, B.C., B.C. Ministry of Transportation. Snow Avalanche Programs, 540-543.

Gibson, L. J. and M. F. Ashby. 1997. Cellular solids: structure and properties. Second edition. Cambridge, Cambridge University Press.

Good, W. 1987. Thin sections, serial cuts and 3-D analysis of snow. International Association of Hydrological Sciences Publication 162 (Symposium at Davos 1986 - Avalanche Formation, Movement and Effects), 35-48.

Gubler, H. 1977. Artificial release of avalanches by explosives. F. Glaciol., 19(81), 419-429.

Hooke, R.LeB. and 11 others. 1980. Mechanical properties of polycrystalline ice: an assessment of current knowledge and priorities for research. Cold Reg. Sci. Technol., 3(4), 263-275.

Hutchinson, J.W., M. E. Mear and J. R. Rice. 1987. Crack paralleling and interface between dissimilar materials. f. Appl. Mech., 54(4), 828-832.

Jamieson, J. B. and C. D. Johnston. 1990. In-situ tensile tests of snow-pack layers. F. Glaciol., 36(122), 102-106.

Jamieson, B. and C. D. Johnston. 2001. Evaluation of the shear frame test for weak snowpack layers. Ann. Glaciol., 32, 59-69.

Kirchner, H.O.K., G. Michot and T. Suzuki. 2000. Fracture toughness of snow in tension. Philos. Mag. A, 80(5), 1265-1272.

Kirchner, H. O. K., G. Michot, H. Narita and T. Suzuki. 2001. Snow as a foam of ice: plasticity, frature and the brittle-to-ductile transition. Philos. Mag. A, 81(9), 2161-2181.

Kirchner, H. O. K., G. Michot and J. Schweizer. 2002a. Fracture toughness of snow in shear and tension. Scripta Mater., 46(6), 425-429. 
Kirchner, H. O. K., G. Michot and J. Schweizer. 2002b. Fracture toughness of snow in shear under friction. Phys. Rev. E, 66(2). (10.1103/PhysRevE.66.027103.

Kojima, K. 1954. [Visco-elastic properties of snow layers.]. Low Temp. Sci., Ser. A, 12, 1-13. [In Japanese with English summary.]

Kronholm, K. and J. Schweizer. 2003. Snow stability variation on small slopes. Cold Reg. Sci. Technol., 37(3), 453-465.

Louchet, F. 2001. A transition in dry-snow slab avalanche triggering modes. Ann. Glaciol., 32, 285-289.

McClung, D. M. 1979. Shear fracture precipitated by strain softening as a mechanism of dry slab avalanche release. F. Geophys. Res., 84(B7), 3519-3526.

McClung, D. M. 1981. Fracture mechanical model of dry slab avalanche release. F. Geophys. Res., 86(B11), 10,783-10,790.

McClung, D. M. and J. Schweizer. 1999. Skier triggering, snow temperatures and the stability index for dry-slab avalanche initiation. F. Glaciol., 45(150), 190-200.

Nixon, W. A. and E. M. Schulson. 1987. A micromechanical view of the fracture toughness of ice. 7. Phys. (Paris), 48, Colloq. Cl, 313-320. (Supplément au 3.
Perla, R. 1977. Slab avalanche measurements. Can. Geotech. 7., 14(2), 206-213. Perla, R., T. M. H. Beck and T. T. Cheng. 1982. The shear strength index of alpine snow. Cold Reg. Sci. Technol., 6(1), 11-20.

Petrenko, V. F. and R.W.Whitworth. 1999. Physics of ice. Oxford, etc., Oxford University Press.

Schweizer, J. 1998. Laboratory experiments on shear failure of snow. Ann. Glaciol., 26, 97-102.

Schweizer, J. 1999. Review of dry-snow slab avalanche release. Cold Reg. Sci. Technol., 30(1-3), 43-57.

Schweizer, J. and C. Camponovo. 2001. The skier's zone of influence in triggering slab avalanches. Ann. Glaciol., 32, 314-320.

Schweizer, J. and C. Camponovo. 2002. The temperature dependence of the effective elastic shear modulus of snow. Cold Reg. Sci. Technol., 35(1), 55-64.

Schweizer, J., J. B. Jamieson and M. Schneebeli. 2003. Snow avalanche formation. Rev. Geophys., 41(4), 1016. (10.1029/2002RG000123.)

Shapiro, L. H., J. B. Johnson, M. Sturm and G. L. Blaisdell. 1997. Snow mechanics: review of the state of knowledge and applications. CRREL Rep. 97-3 